\title{
Electrocatalytical Oxidation of Methanol on (Zn or Cu/Natural Phosphate/ Iron) Electrode
}

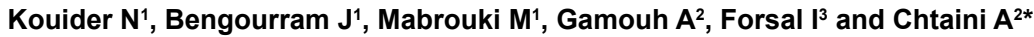 \\ ${ }^{1}$ Laboratoire Génie Industriel, Faculté des Sciences et Techniques de Béni Mellal, Morocco \\ ${ }^{2}$ Equipe d.Electrochimie Moléculaire et Matériaux Inorganiques, Faculté des Sciences et Techniques de Béni Mellal, Morocco \\ ${ }^{3}$ Laboratoire de Chimie Organique et Analytique, Faculté des Sciences et Techniques de Béni Mellal, Morocco Cruz do Sul, Brazil
}

\begin{abstract}
Two new electrodes were prepared and characterized electrochemically; Zn/NP//ron and Cu/NP/lron, for a direct methanol fuel cell (DMFC). Themorphology and structure of the catalyst layer were analyzed by optical microscopy. The catalyst coating layer shows an alloy character. The results show that, the oxidation of methanol is catalysed by the formation of copper oxides on the surface of the $\mathrm{Cu} / \mathrm{NP} /$ Iron.
\end{abstract}

Keywords: Electrodeposit; Methanol oxidation; Catalyst; SQWV

\section{Introduction}

Fuel cells are efficient and environmentally acceptable conversion devices. Electric current is generated in the fuel cell by the direct electrochemical oxidation of either hydrogen (proton exchange membrane fuel cell, PEM) or methanol (Direct Methanol Fuel Cell, DMFC). The electrochemical processes that yield energy are essentially pollution free. Water formed during the operation of the device is beneficial in space travel and submarines. Applications of fuel cells are diverse ranging from stationary (individual homes or district schemes) or mobile (transportation as cars, buses, etc.), mobile phones and lap top computers $[1,2]$. Hydrogen is currently the only practical fuel for use in the present generation of fuel cells. The main reason for this is this is its high electrochemical reactivity compared with that of the more common fuels from which it is derived, such as hydrocarbons, alcohols, or coal. Also, its reaction mechanisms are now rather well understood [3,4] and are characterized by the relative simplicity of its reaction steps, which lead to no side products. Pure hydrogen is attractive as a fuel, because of its high theoretical energy density, its innocuous combustion product (water), and its unlimited availability so long as a suitable source of energy is available to decompose water. One of the disadvantages of pure hydrogen is that it is a low density gas under normal conditions, so that storage is difficult and requires considerable excess weight compared with liquid fuels.

Methanol has been considered for fuel cell power generation for a number of years because it can be processed into a hydrogen-rich fuel gas fairly easily and efficiently by steam or auto thermal reforming. Methanol, as a liquid fuel is easily transported and stored in comparison to hydrogen gas.

The methanol fuel has a superior specific energy density $(6000$ $(\mathrm{Wh} / \mathrm{Kg})$ in comparison with the best rechargeable battery, lithium polymer and lithium ion polymer $(600(\mathrm{Wh} / \mathrm{Kg})$ systems. This means longer conservation times using mobile phones, longer times for use of laptop computers and more power available on these devices to support consumer demand. Another significant advantage of the direct methanol fuel cells over the rechargeable battery is its potential for instantaneous refuelling [5-7].

In this work we propose to coat stainless steel surfaces with another material as a natural phosphate phase in order to form satisfactory modified electrodes for eventually anode for methanol fuel cell. To fulfill the purpose of strong adhesion of natural phosphate on stainless steel, coating by electrochemical technique is interesting as a simple technique and can be achieved at room temperature. Based upon the solubility product constant of natural phosphate at $25^{\circ} \mathrm{C}$, it can be estimated that the matrices can be easily deposited on stainless steel substrate by electrochemical methods.

\section{Experimental}

\section{Reagent}

A Natural Phosphate (NP) used in this work was obtained in the Khouribga region (Morocco) [8]. Prior to use, this material was treated by techniques involving attrition, sifting, calcinations $\left(900^{\circ} \mathrm{C}\right)$, washing, and recalcination.

\section{Sample preparation}

Stainless steel (type $316 \mathrm{~L}$ ) plate was cut into rectangular strips with typical dimensions of $1 \mathrm{~cm}^{2}$. The chemical composition of stainless steel investigated in this work is: (wt\%) $\mathrm{C} \leq 0.02$, Mo: 3.5-4.5, Cr: $24-$ 26 , Ni: 6-8, N $\geq 0.25$, Fe remainder. Strips were abraded with $\mathrm{SiC}$ paper in successive grades from 400, 600 up to 1200 grit and then cleaned in distilled water and dried.

The current was maintained by a galvanostat with a function generator. The anode electrode was a platinum wire, and a stainless steel electrode was used as cathode. Then, the electrodes were immersed in a glass chamber containing electrolyte of natural phosphate and/or $\mathrm{ZnSO}_{4}$, and subjected to anodic oxidation by applying $100 \mathrm{~mA}$ for 6 hours NP and $30 \mathrm{~min}$ for $\mathrm{Zn}$ electrodeposition.

\section{Modified electrodes characterization}

Optical microscope in reflection was used to observe the morphology of samples. Electrochemical experiments were carried out with a voltalab potentiostat (model PGSTAT 100, Eco Chemie

*Corresponding author: Chtaini A, Equipe d.Electrochimie Moléculaire et Matériaux Inorganiques, Faculté des Sciences et Techniques de Béni Mellal, Morocco, Tel: 34999941256; E-mail: a.chtaini@usms.ma

Received November 13, 2015; Accepted December 03, 2015; Published December 13,2015

Citation: Kouider N, Bengourram J, Mabrouki M, Gamouh A, Forsal I, et al. (2015) Electrocatalytical Oxidation of Methanol on ( $\mathrm{Zn}$ or Cu/Natural Phosphate/Iron) Electrode. J Material Sci Eng 5: 218. doi:10.4172/2169-0022.1000218

Copyright: @ 2015 Kouider N, et al. This is an open-access article distributed unde the terms of the Creative Commons Attribution License, which permits unrestricted use, distribution, and reproduction in any medium, provided the original author and source are credited. 
Citation: Kouider N, Bengourram J, Mabrouki M, Gamouh A, Forsal I, et al. (2015) Electrocatalytical Oxidation of Methanol on (Zn or Cu/Natural Phosphate/Iron) Electrode. J Material Sci Eng 5: 218. doi:10.4172/2169-0022.1000218

B. V., Utrecht, The Netherlands) driven by the general purpose electrochemical systems data processing software (voltalab master 4 software). The electrochemical cell was configured to work with three- electrodes, using NP and/or Zn-NP modified stainless steel as the working, platinum plate for counter, and saturated calomel (SCE) as reference electrodes. Impedance measurements were made in the frequency range between $10 \mathrm{mHz}$ and $100 \mathrm{KHz}$ with five points per decade at the corrosion potential. A sine wave with $10 \mathrm{mV}$ amplitude was used to perturb the system. The Nyquist diagrams obtained were automatically controlled by computer programs. The electrolytical solution used $\left(0.1 \mathrm{M} \mathrm{H}_{2} \mathrm{SO}_{4}\right)$ as prepared from distilled and deionised water. All tests were performed at $25^{\circ} \mathrm{C}$.

\section{Results and Discussion}

\section{Zn/NP/Iron electrode}

The surface structure of prepared electrodes (NP/Iron and Zn/ NP/Iron) was observed using optical reflexion microscopy (Figure 1). The phosphate film deposited on the surface of the iron appears continuously and forms a non homogeneous matrix, consisting of crystals of the order of $100 \mu \mathrm{m}$ and $400 \mu \mathrm{m}$. In the case of $\mathrm{Zn} / \mathrm{NP} / \mathrm{Iron}$, the film exhibited a porous microstructure with micro pores, which were relatively well separated and homogeneously distributed over the surface. The film formed is continued and not disintegrated from substrate surface.

\section{Methanol oxidation at modified electrodes}

The potentiostatic polarization curves and table of measurement results for the test specimen, registered in $0.1 \mathrm{M} \mathrm{H}_{2} \mathrm{SO}_{4}$ solution containing a small amount of methanol $(0.5 \mu \mathrm{mol})$, are shown in Figure 2 and Table 1 respectively. We can see in Table 1 , the polarization resistance value drops slightly in the presence of methanol, which can be explained by the activity of the new electrode with respect to

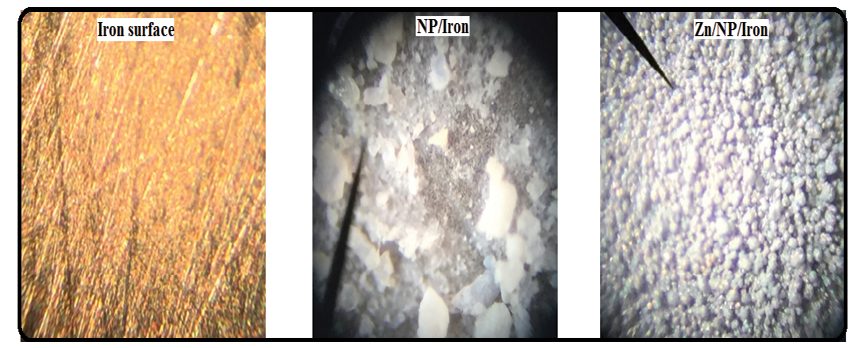

Figure 1: Typical AFM images of electrodeposited films into stainless steel plates.

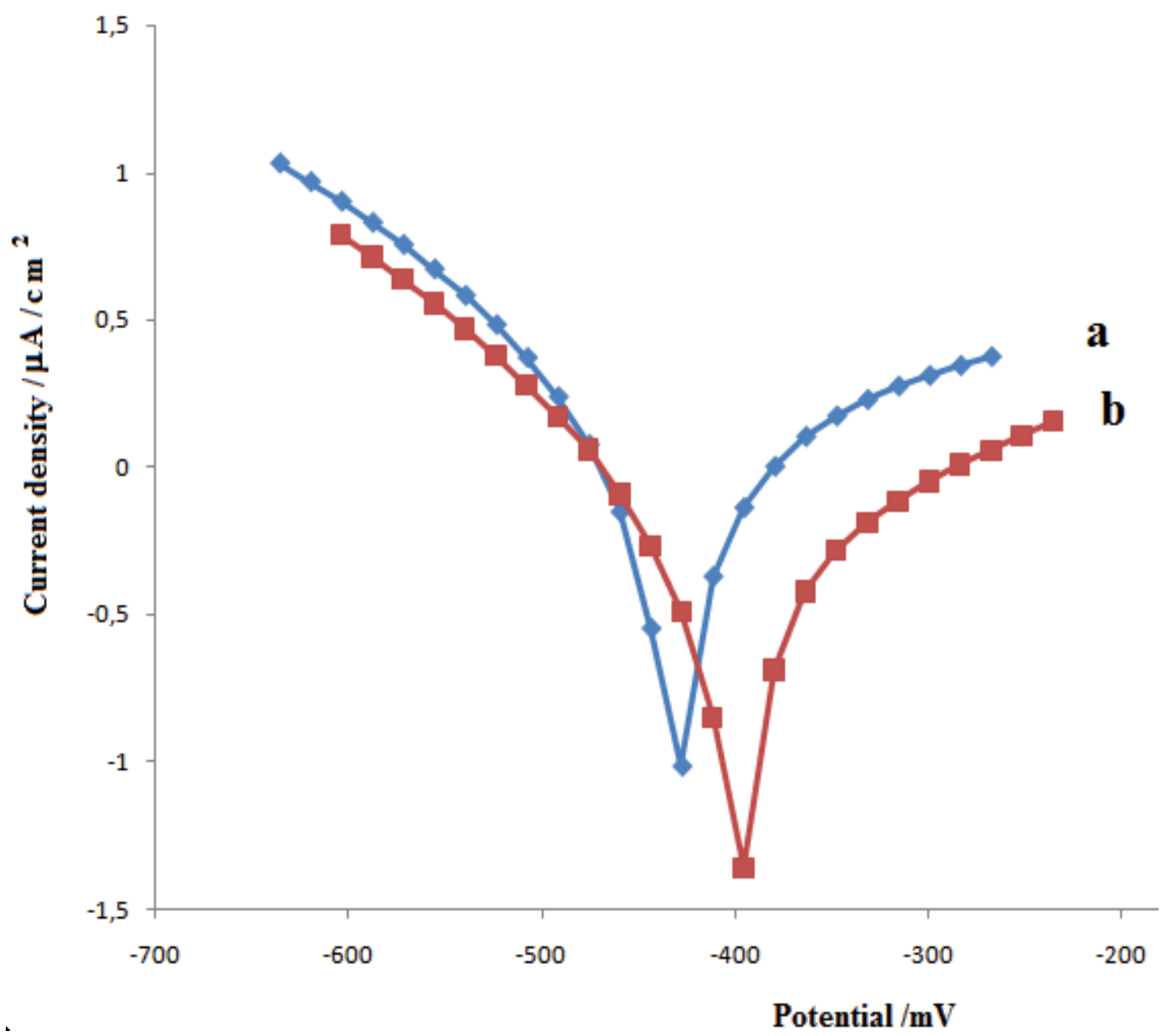

Figure 2: Polarization curves of $\mathrm{Zn} / \mathrm{NP} / /$ ron electrode in $0.1 \mathrm{M} \mathrm{H}_{2} \mathrm{SO}_{4}$ solution, (a) without methanol, (b) with methanol. 
Citation: Kouider N, Bengourram J, Mabrouki M, Gamouh A, Forsal I, et al. (2015) Electrocatalytical Oxidation of Methanol on (Zn or Cu/Natural Phosphate/Iron) Electrode. J Material Sci Eng 5: 218. doi:10.4172/2169-0022.1000218

\begin{tabular}{|c|c|c|c|c|}
\hline Samples & $\mathbf{E}(\mathbf{i}=\mathbf{0}) \mathbf{~ M v}$ & $\mathbf{R p ~ o h m . c ^ { 2 }}$ & $\boldsymbol{\beta a ~} \mathbf{~ m V}$ & $\boldsymbol{\beta c ~} \mathbf{~ m V}$ \\
\hline Zn/NP/Iron without methanol & $-356,6$ & 131,69 & 389,1 & $-215,5$ \\
\hline Zn/NP/Iron in presence of methanol & $-391,3$ & 92,83 & 436,5 & $-221,1$ \\
\hline
\end{tabular}

Table 1: Summary of electrode polarization results for the methanol oxidation.

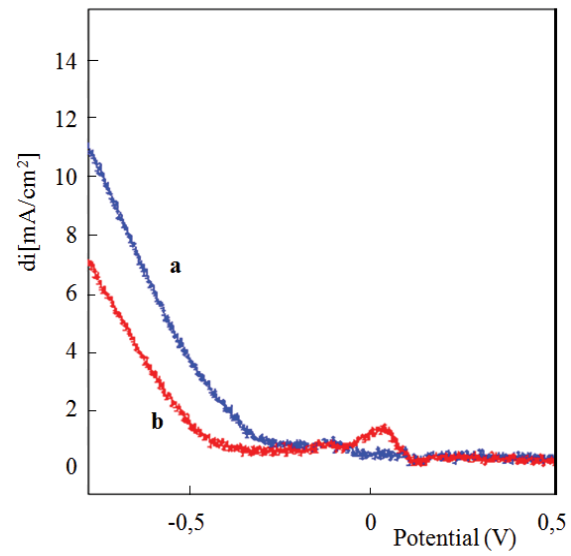

Figure 3: Square wave voltammetry in $\mathrm{N}_{2}$ saturated $0.1 \mathrm{M} \mathrm{H}_{2} \mathrm{SO}_{4}$, recorded for $\mathrm{Zn} / \mathrm{NP} /$ Iron electrode in presence of methanol $(0.5 \mu \mathrm{mol}$, curve $\mathrm{b})$, and in absence of methanol (curve a). the methanol oxidation. Polarization resistance $(\mathrm{Rp})$ is the transition resistance between the electrodes and the electrolyte. In other words, an increased resistance to the flow of current in a voltaic cell is caused by chemical reactions at the electrodes. Polarization results in a reduction of the electric potential across the voltaic cell. An electrode is polarized when its potential is forced away from its value at open circuit or corrosion potential. Polarization of an electrode causes current to flow due to electrochemical reactions that it induces at the electrode surface.

Figure 3 shows the square wave voltammograms (SWV) recorded for $\mathrm{Zn} / \mathrm{NP} /$ Iron electrode in $0.1 \mathrm{M} \mathrm{H}_{2} \mathrm{SO}_{4}$ solution containing $0.5 \mu \mathrm{mol}$ of methanol. The Figure shows the existence of a well-defined peak at potential value about $0.1 \mathrm{~V}$. It was suggested that this peak corresponds to methanol oxidation.

The Nyquist plots for the prepared electrode, recorded in $\mathrm{H}_{2} \mathrm{SO}_{4}$ solution containing or not methanol, are presented in Figure 4. In both cases, the locus of Nyquist plots is regarded as one part of semi-circle, who is struggling to close, due to the very high resistance.

\section{$\mathrm{Cu} / \mathrm{NP} /$ Iron electrode}

The surface structure of $\mathrm{Cu} / \mathrm{NP} / \mathrm{Iron}$ electrode was observed using reflexion optical microscopy (Figure 5). As we can see, the copper is deposited on the active sites, which are scattered along the phosphate surface. Clusters of copper, deposited electrochemically on the phosphate matrix have a porous and roughness structure.

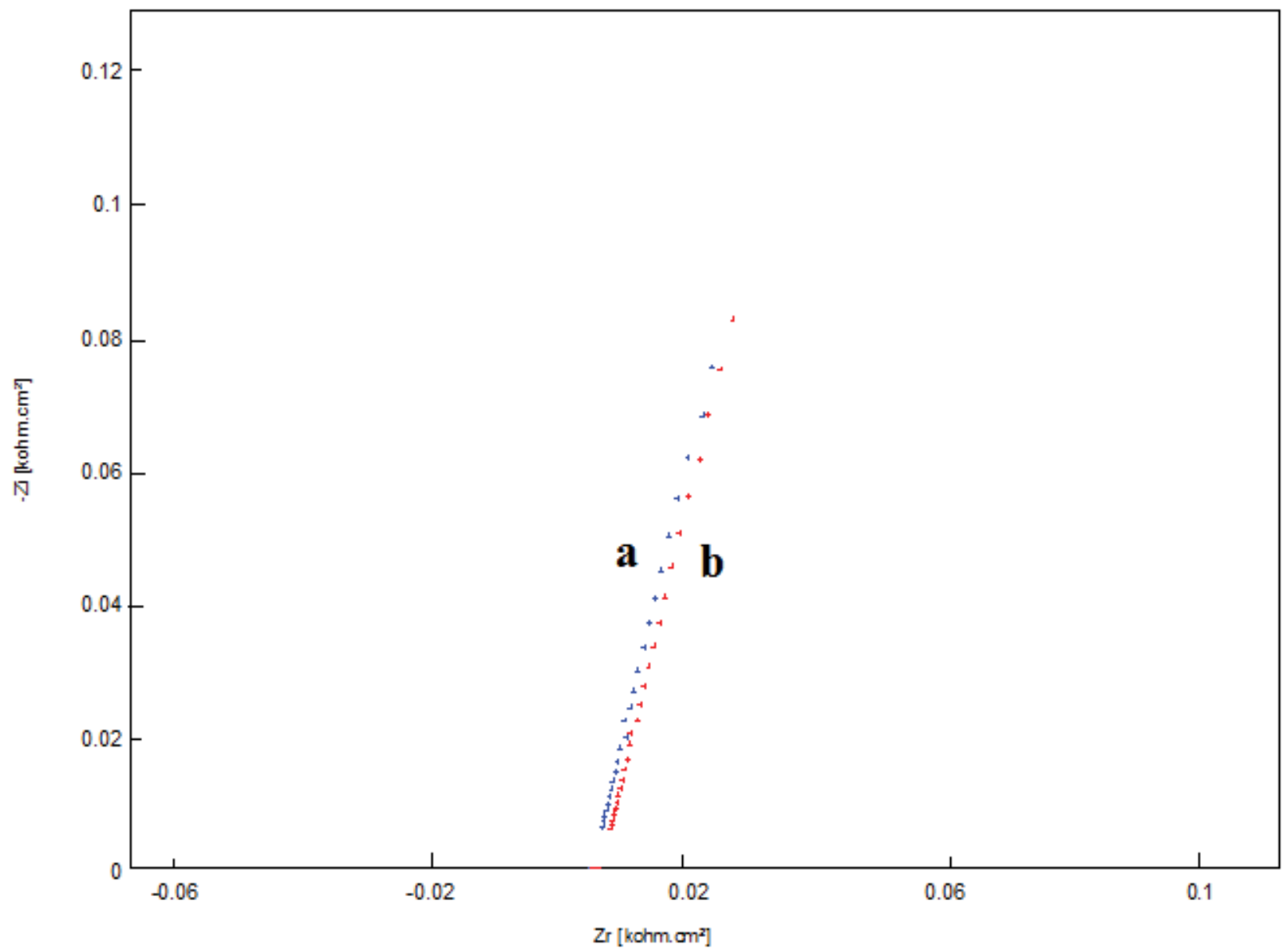

Figure 4: Electrochemical impedance spectroscopy for $\mathrm{Zn} / \mathrm{NP} /$ Iron electrode, in $0.1 \mathrm{M} \mathrm{H}_{2} \mathrm{SO}_{4}$, containing methanol $0.5 \mu$ mol (curve b), and without methanol (curve a) 
Citation: Kouider N, Bengourram J, Mabrouki M, Gamouh A, Forsal I, et al. (2015) Electrocatalytical Oxidation of Methanol on (Zn or Cu/Natural Phosphate/Iron) Electrode. J Material Sci Eng 5: 218. doi:10.4172/2169-0022.1000218

In contrast to zinc, the copper deposited on the surface of the steel electrode, exhibits a slight increase of the polarization resistance at the electro oxidation of methanol (Table 2). To explain this phenomenon, we appealed to the SWV, shown in Figure 5. We can find that the presence of methanol in the electrolytic solution causes the growth of the copper oxidation, which appears to $0.1 \mathrm{~V}$. This leaves suggest that the oxidation of phenol is stimulated by the copper oxides. The locus of Nyquist plots (Figures 6 and 7) has the shape of semi-circle, in the absence and presence of methanol, the diameter of the semicircle correspond to the polarization resistance, which means that the methanol oxidation reaction is catalyzed by the copper oxide.

\section{Conclusion}

The current study introduces novel anodes for the electro-catalytic oxidation of methanol in $\mathrm{H}_{2} \mathrm{SO}_{4}$ medium. The $\mathrm{Zn} / \mathrm{NP} / \mathrm{Iron}$ and $\mathrm{Cu} / \mathrm{NP} /$ Iron anodes prepared by the potentiostatic deposition respectively, of

\begin{tabular}{|c|c|c|c|c|c|}
\hline Echantillon S & $\begin{array}{c}\mathbf{E}(\mathbf{i}=\mathbf{0}) \\
\mathbf{m V}\end{array}$ & $\begin{array}{c}\mathbf{R p} \text { ohm. } \\
\mathbf{c m}^{\mathbf{2}}\end{array}$ & $\begin{array}{c}\mathbf{I} \text { Corr } \mathbf{\mu A} / \\
\mathbf{c m}^{\mathbf{2}}\end{array}$ & $\boldsymbol{\beta a ~} \mathbf{~ m V}$ & $\mathbf{\beta c} \mathbf{~ m V}$ \\
\hline $\begin{array}{c}\text { Acier316L/ NP/Cuivre sans } \\
\text { Méthanol }\end{array}$ & $-439,5$ & 109,30 & 511,7 & 340,1 & $-195,5$ \\
\hline $\begin{array}{c}\text { Acier 316L/ NP/Cuivre Avec } \\
\text { Méthanol }\end{array}$ & $-424,1$ & 113,64 & 337,3 & 244,9 & $-171,1$ \\
\hline
\end{tabular}

Table 2: Summary of electrode polarization results for the methanol oxidation.

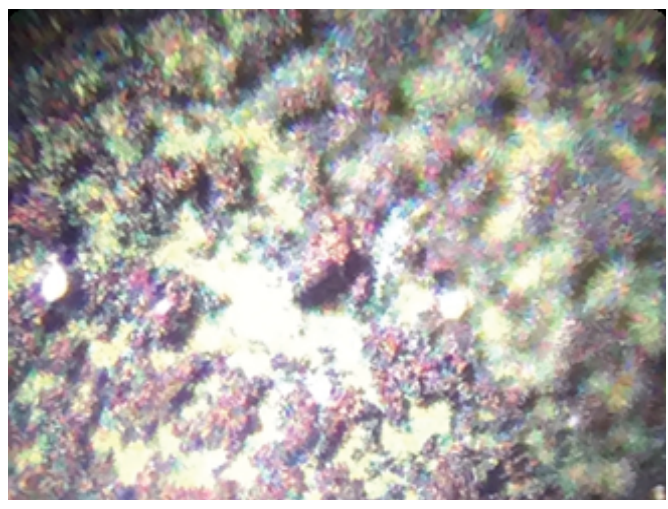

Figure 5: Typical AFM images of electrodeposited films into stainless steel plates.

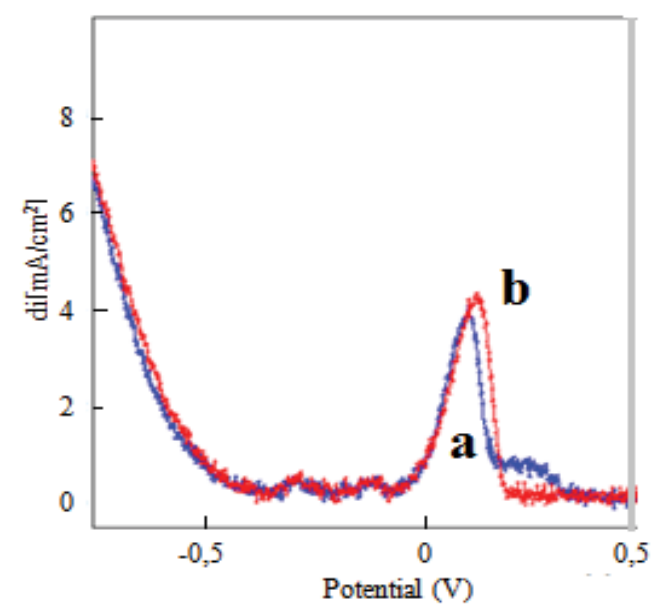

Figure 6: Square wave voltammetry in $\mathrm{N}_{2}$ saturated $0.1 \mathrm{M} \mathrm{H}_{2} \mathrm{SO}_{4}$, recorded for $\mathrm{Zn} / \mathrm{NP} /$ Iron electrode in presence of methanol $(0.5 \mu \mathrm{mol}$, curve $\mathrm{b})$, and in absence of methanol (curve a).

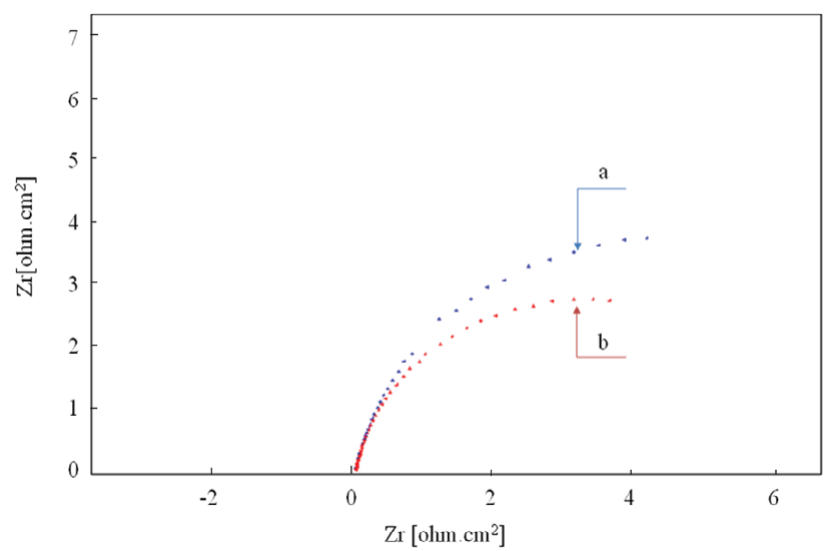

Figure 7: Electrochemical impedance spectroscopy for $\mathrm{Cu} / \mathrm{NP} /$ Iron electrode in $0.1 \mathrm{M} \mathrm{H}_{2} \mathrm{SO}_{4}$, containing methanol $0.5 \mu \mathrm{mol}$ (curve b), and without methano (curve a).

natural phosphate and zinc or copper on iron surface are good catalysts for methanol electro-oxidation. In the case of copper this reaction is promoted by the formation of copper oxides on the surface.

\section{References}

1. Neel PJ (2008) MVC Sastry Hall, NCCR.

2. Carabineiro SAC, Thompson DT (2007) Catalytic Applications of Gold Nanotechnology in Nanoscience and Technology. In: Heiz U, Landman U (eds.) Nanocatalysis. Springer-Verlag, Berlin Heidelberg.

3. Appleby AJ, Foulkes FR (1989) Fuel Cell Handbook. Van Nostrand Reinhold, New York.

4. Chtaini A (1993) Thesis, Poitiers (French).

5. Baglio V, Di Blasi A, Modica E, Creti P, Antonucci V, et al. (2006) Electrochemical Analysis of Direct Methanol Fuel Cells for Low Temperature Operation. Int J Electrochem Sci 1: 71-79.

6. Shukla AK, Christensen PA, Hamnett A, Hogarth MP (1995) A vapour-feed direct-methanol fuel cell with proton-exchange membrane electrolyte. J Power Sources 55: 87-91.

7. Antolini E, Salgado JRC, Santos LGRA, Garcia G, Ticianelli EA , et al. (2006) Carbon supported $\mathrm{Pt}-\mathrm{Cr}$ alloys as oxygen-reduction catalysts for direct methanol fuel cells. J Appl Electrochem 36: 355-362.

8. Natural phosphate (NP) Comes Khouribga Region (Morocco). It is readily available from CERPHOS, Casablanca, Morocco. 